\title{
To Tree or Not to Tree: Cultural Views from Ancient Romans to Modern Ecologists
}

\author{
Milena Holmgren $^{1 *}$ and Marten Scheffer ${ }^{2}$
}

\begin{abstract}
${ }^{1}$ Resource Ecology Group, Wageningen University, P.O. Box 47, 6700 AA Wageningen, The Netherlands; ${ }^{2}$ Aquatic Ecology and Water Quality Management Group, Wageningen University, P.O. Box 47, 6700 AA Wageningen, The Netherlands
\end{abstract}

\begin{abstract}
Few things are more defining in a landscape compared to the absence or presence of trees, both in aesthetic and in functional terms. At the same time, tree cover has been profoundly affected by humans since ancient times. It is therefore not surprising that opinions about deforestation and colonization of landscapes by trees have always been strong. Although loss of forests is often lamented, there is also profound cultural affection for open landscapes including some that have been deforested in the past. Here we take a historical view on perceptions of changing tree cover, and subsequently argue that the current ecological literature on forest-sa-
\end{abstract}

\section{INTRODUCTION}

As ecologists, we try to understand the networks of interactions between organisms and their environment, and the processes that explain the structure and functioning of ecosystems. From a human perspective, we classify these ecosystem features and processes into different types of ecosystem services and use this concept to com-

Received 18 April 2016; accepted 23 September 2016; published online 17 October 2016

Author contributions Milena Holmgren and Marten Scheffer have contributed equally to the conception and writing of this manuscript.

*Corresponding author; e-mail: Milena.Holmgren@wur.nl vanna-grassland transitions is not immune to value-laden perspectives. So far, ecosystem science has not done enough to analyze the effects of tree cover changes on ecosystem services and indicators of human well-being. Until these analyses are done, debates about forested versus open landscapes will be clashes of values rather than scientific evaluations. We discuss how ecosystem science may contribute to developing this field.

Key words: ecosystem services; forest; grassland; land degradation; savanna; tree encroachment; visions of nature. municate the implications of ecological changes to society (Millennium Ecosystem Assessment 2005). However, framing conservation and management strategies based on an ecosystem service perspective remains challenging. An uneven knowledge of ecosystem functions, as well as contrasting differences in how ecosystem services are perceived and valued across social groups, limits decision making on trade-offs associated to the delivery of different types of ecosystem services (Butterfield and others 2016; Palomo and others 2016). These decisions, in turn, not only change natural landscapes and social structures but, given sufficient time, they also modify our own perception of nature in a coevolving process that characterizes socioecological systems (Ostrom 2008). This process has likely been 
stronger in ecosystems in which people and nature have longer co-existed. Reflecting on this, we illustrate how changes in tree dominance have been historically perceived to highlight how ecosystem science can contribute to current ecological debates on conservation and restoration of grasslands, woodlands, and forests.

\section{Historical Laments of Deforestation}

Substantial deforestation probably started with Neolithic cultures developing sedentary agriculture-based lifestyles worldwide. However, the first descriptions of how the loss of trees from landscapes are perceived come from classical Roman and Greek writings. Although the precise extent of deforestation in those days remains somewhat uncertain, several lines of evidence indicate that many regions around the Mediterranean Basin faced major deforestation (Hughes 2011). This did not leave people untouched, as illustrated by a famous passage in Plato's Critias where he laments degradation of the Greek hills as he perceived it in 360 years BC:

'... in those days the country ... yielded far more abundant produce. .... during all this time and through so many changes, there has never been any considerable accumulation of the soil coming down from the mountains, as in other places, but the earth has fallen away all round and sunk out of sight. The consequence is, that in comparison of what then was, there are remaining only the bones of the wasted body, as they may be called, as in the case of small islands, all the richer and softer parts of the soil having fallen away, and the mere skeleton of the land being left. But in the primitive state of the country, its mountains were high hills covered with soil, and the plains, as they are termed by us, of Phelleus were full of rich earth, and there was abundance of wood in the mountains. Of this last the traces still remain, for although some of the mountains now only afford sustenance to bees, not so very long ago there were still to be seen roofs of timber cut from trees growing there, which were of a size sufficient to cover the largest houses; and there were many other high trees, cultivated by man and bearing abundance of food for cattle. Moreover, the land reaped the benefit of the annual rainfall, not as now losing the water which flows off the bare earth into the sea, but, having an abundant supply in all places, and receiving it into herself and treasuring it up in the close clay soil, it let off into the hollows the streams which it absorbed from the heights, providing everywhere abundant fountains and rivers, of which there may still be observed sacred memorials in places where fountains once existed; and this proves the truth of what I am saying' (Plato 360 $\mathrm{BC}$ as translated by Benjamin Jowett).

Since then, accounts of worries about deforestation are recurrent in written literature, nature, and history studies. For instance, in the seventeenth century, naturalist John Evelyn wrote that deforestation in England had reached epidemical proportions, calling for laws to ensure the preservation of Woods (Evelyn, John. Sylva, or A Discourse of Forest-Trees, and the Propagation of Timber in His Majesties Dominions. London: Royal Society, 1664. Quoted in Hutchings 2007).

Possibly one of the most influential thinkers about forest was Alexander von Humboldt. As Andrea Wulf describes in her recent biography (Wulf 2015), Humboldt traveled through Latin America between 1799 and 1804, seeing how colonial deforestation left the land barren, with soils washed away and lakes and rivers drained. He was the first to understand what we now describe as ecosystem services of the forest, enriching the atmosphere with moisture, cooling the air, and retaining water in the soils. Most importantly, he communicated his love for nature, as well as his warnings in ways that reached the masses. Humboldt became the visionary father of environmentalism, as reflected by the fact that commemorations of his birth a century later attracted impressive crowds around the world, and memories of his death have brought scientists together ever since.

Also, Darwin was much inspired by the work of Humboldt, and like Humboldt contemplated the causes as well as the consequences of deforestation. For instance, describing his visit to the island of St. Helena, Darwin writes in The Voyage of The Beagle in 1836 (Darwin 1845):

'The history of the changes, which the elevated plains of Longwood and Deadwood have undergone, as given in General Beatson's account of the island, is 
extremely curious. Both plains, it is said, in former times were covered with wood, and were therefore called the Great Wood. So, late as the year 1716 there were many trees, but in 1724 the old trees had mostly fallen; and as goats and hogs had been suffered to range about, all the young trees had been killed. It appears also from the official records, that the trees were unexpectedly, some years afterwards, succeeded by a wire grass, which spread over the whole surface. General Beatson adds that now this plain "is covered with fine sward, and is become the finest piece of pasture on the island." The extent of surface, probably covered by wood at a former period, is estimated at no less than two thousand acres; at the present day scarcely a single tree can be found there. It is also said that in 1709 there were quantities of dead trees in Sandy Bay; this place is now so utterly desert, that nothing but so well attested an account could have made me believe that they could ever have grown there. The fact, that the goats and hogs destroyed all the young trees as they sprang up, and that in the course of time the old ones, which were safe from their attacks, perished from age, seems clearly made out. Goats were introduced in the year 1502; eighty-six years afterwards, in the time of Cavendish, it is known that they were exceedingly numerous. More than a century afterwards, in 1731, when the evil was complete and irretrievable, an order was issued that all stray animals should be destroyed. It is very interesting thus to find, that the arrival of animals at St. Helena in 1501, did not change the whole aspect of the island, until a period of two hundred and twenty years had elapsed: for the goats were introduced in 1502, and in 1724 it is said "the old trees had mostly fallen." There can be little doubt that this great change in the vegetation affected not only the land-shells, causing eight species to become extinct, but likewise a multitude of insects.'

Although interested in everything, Darwin was generally not very enthusiastic about treeless landscapes. For instance, going on land in Mal- donado, Uruguay, he describes: 'an open slightlyundulating country, covered by one uniform layer of fine green turf, on which countless herds of cattle, sheep, and horses graze. ... The scenery is very uninteresting; there is scarcely a house, an enclosed piece of ground, or even a tree, to give it an air of cheerfulness.' Although he can see some charm in it 'Yet, after being imprisoned for some time in a ship, there is a charm in the unconfined feeling of walking over boundless plains of turf.'

\section{Coming to Love Deforested Landscapes}

Even though an observed loss of trees has been lamented throughout history, over time mankind usually identifies culturally to the new situation, and starts loving the open landscapes. For instance, many of Europe's deforested landscapes have become a beloved view. A good example is the English Lake District, where the rolling hills spiritually hosted the English romantic movement. Especially the writings of William Wordsworth have inspired the minds of generations when it comes to appreciating this pastoral, once forested, landscape. Consider his poem 'Written in March' (1801) (Wordsworth 1888):

The cock is crowing,

The stream is flowing,

The small birds twitter,

The lake doth glitter

The green field sleeps in the sun;

The oldest and youngest

Are at work with the strongest;

The cattle are grazing,

Their heads never raising;

There are forty feeding like one!

Like an army defeated

The snow hath retreated,

And now doth fare ill

On the top of the bare hill;

The ploughboy is whooping- anon-anon:

There's joy in the mountains;

There's life in the fountains;

Small clouds are sailing,

Blue sky prevailing;

The rain is over and gone!

The UK attempt to have the region that inspired Wordsworth recognized as a world heritage site has been criticized as romanticizing an ecological disaster by critics as George Monbiot (2013): 'I revere Wordsworth the poet, but not his view of farming as a benign force. The Lakes fells don't need world heritage status - just fewer sheep.' However, such 
are minority views on an otherwise widely beloved human-made landscape.

Meanwhile, vast regions of Europe are seeing an expansion of forests, largely due to agricultural abandonment of marginal areas such as mountainous regions (MacDonald and others 2000). This goes with a loss of traditional farming practises, such as transhumant pastoralism, where the pastor spends the summer with the livestock in the high mountains and regresses in fall. In addition to this cultural loss, there are concerns over a loss of biodiversity as alpine meadows with their characteristic flora and fauna decline, fuelling efforts to design policies that may halt the recovery of forests (MacDonald and others 2000). These are places in which people have shaped the landscape and in turn shaped a strong sense of local identity and belonging (Rössler 2006). As a consequence, transitions from these cultural landscapes to natural systems are almost unavoidably perceived as a painful loss as reflected in this poetic analysis of Pyrenean pastoralists views (Fernández-Giménez 2015):

The biggest change is the shrubs, the brush

It is climbing and it is winning

The middle pastures

It is eating them

Enebro, aliaga, the pines as well

All of them are growing, growing, growing.

It is due to the lack of people

The brush in the middle pastures

We used to be there, all of us

From October to December

And we made small fires

Burning the brush

One here, one there

And we had our camps

And cut our wood

With the decline in livestock

The people have disappeared

Now we don't burn

It's not allowed

Not allowedThis does a lot of damage

\section{Echoes of Cultural Preferences in ECOLOGY}

Much more may be said about the historical and current human attitudes to the wax and wane of tree cover in landscapes. However, we now turn to a reflection on the position of modern ecology amidst these societal dynamics. There is little dispute over the value of maintaining natural forests throughout the world. By contrast, there is a dichotomy between strongly held contrasting positions with respect to the desirability of a recovery of trees in open landscapes, even if those are culturally deforested. This raises the question of whether the science of ecology now is entirely immune to such biases. Of course as scientists we should be. As Baruch Spinoza already noted, dogma is the greatest enemy of reason. Still, even for welltrained scientists it can remain challenging to be entirely dispassionate, as Chamberlin reminded us subtly more than a century ago in his famous plea for maintaining multiple working hypotheses (Chamberlin 1897): 'Love was long since represented as blind, and what is true in the personal realm is measurably true in the intellectual realm.'

So, how are we doing when it comes to our research and recommendations on the expansion of trees in landscapes? In our view, not so well. We seem to be running the risk of losing precious time and energy in controversies fuelled by a mix of implicit biases and unclear communication. Ecology has a track record of long and winding discussions over issues such as the relevance of density dependence, top-down control, competition, stability, or neutrality. In the end, one sometimes wonders how much scientific understanding such controversies really produced. Although these past discussions were about topics of mostly academic interest, decisions on tree expansion have enormous societal and ecological implications. Therefore, we cannot afford to lose much time. A good example of the current dynamics of confusion is the current debate triggered by the publication of the online map "A World of Opportunity for Forest and Landscape Restoration Map" (Laestadius and others 2011). This map was meant to identify the opportunities for landscape restoration worldwide by comparing the current extent of forests and woodlands with the potential surface for these biomes based on climate conditions. The result was a surface larger than South America. This initiative was supported by a broad group of international organizations concerned with land degradation, biodiversity loss, climate change mitigation, and human well-being. Despite this broad consortium, the map has triggered strong reactions among scientists working on ancient open grasslands and savannas warning against massive afforestation programs justified by this map. An important article with the self-explana- 
Table 1. Key Questions that May Structure Research Needed to Provide the Information Needed to Decide on the Optimal Tree Cover of a Landscape

1. How does tree cover and composition affect the different supporting, provisioning, regulating and cultural ecosystem services? (see Figure 1 for hypothetical examples)

2. How does the resilience of ecosystem services under climate change vary with tree cover?

3. How do socio-economic incentives and cultural backgrounds mediate the perception of ecosystem services?

4. What are the ecological and the social bridges and barriers to manage changes in tree cover pro-actively in the face of climate change?

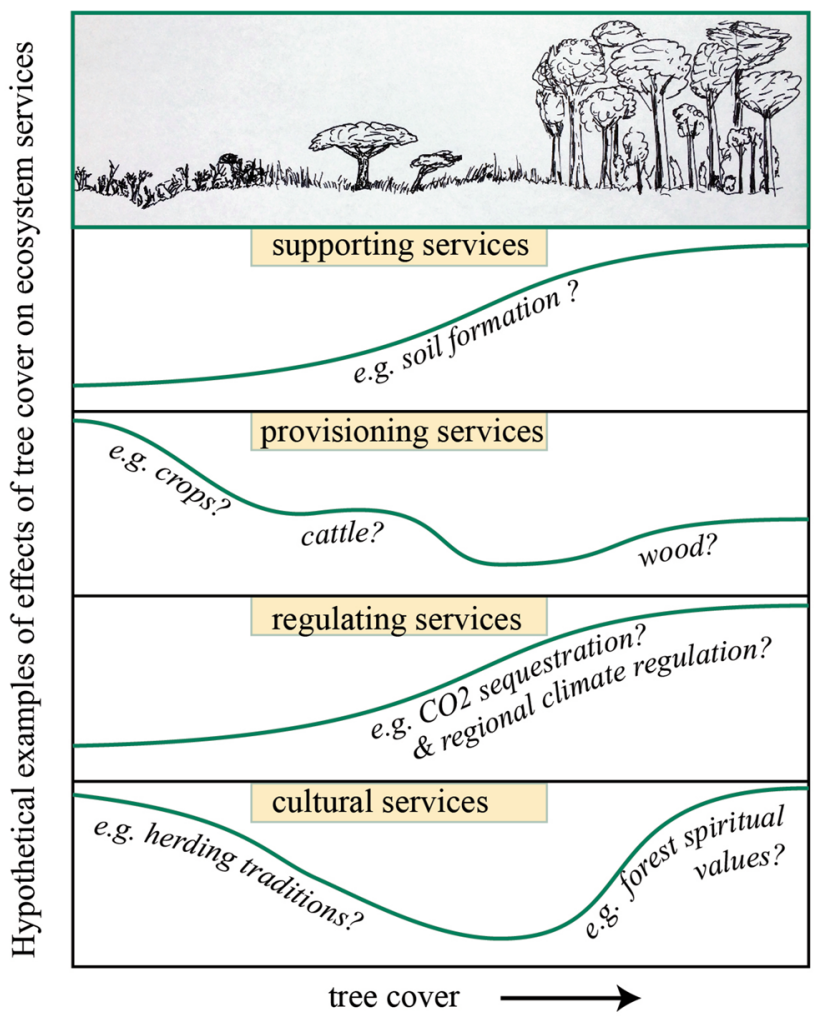

tory title 'Tyranny of Trees in Grassy Biomes' (Veldman and others 2015) explains the worry about the potential loss of biodiversity and other ecosystem services as tree canopy closes in these systems. Clearly, we are far from an integrative dialogue. This may in part be due to a lack of clarity in the definitions of concepts such as 'closed forests,' 'open forests,' and 'woodlands,' and the relative role of natural disturbance regimes that maintain the open structure, functioning, and diversity of landscapes with less tree cover. However, it seems to us that the ferocity of positions may also have to do with tacit love that we all have for particular landscapes, be it open or forested. Indeed, Hobbs (2016) recently highlighted the widespread subjectivity behind the definitions of ecosystem degradation and the underlying premises of restoration projects.
Figure 1. Hypothetical effects of tree cover on the four classes of ecosystem services in an imaginary landscape.

\section{Prospect}

Will it be possible to join forces across communities and lay out the possibilities and limitations of tree expansion, as well as the effects on society and its biosphere in the broadest possible sense including elements ranging from global biodiversity and cultural heritage to atmospheric carbon levels? Certainly, there are very good reasons to prevent tree expansion in many settings. Open landscapes, even those that are human-made, contain unique communities of plants and animals, elevating the biodiversity especially in landscapes consisting of patchworks of woody and open habitats. Also, human-made open landscapes are often associated with unique herding practises and other cultural heritage in terms of agricultural practises. However, we should be aware that conservation is intrinsi- 
cally backward-looking, an approach that is not necessarily most productive when it comes to making the best of ecosystem services in a globally changing world. For example, the almost treeless landscapes that Darwin witnessed around Uruguay are kept empty by cattle. Since the little ice-age, the climate has become moister in the region, and as Darwin already noted both the climate and the soils are conductive to productive tree growth (Bernardi and others 2016). Although some patchy tree cover would most likely benefit biodiversity as well as animal welfare and production (through nitrogen fixation and reduced heat stress on animals and grass), the topic of expanding tree cover meets resistance in policy as well as scientific literature.

Climate change in the Anthropocene has started shifting the distributional ranges of plant and animal species (Parmesan 2006; Chen and others 2011). This trend will likely accelerate as regional rainfall and temperature patterns shift. As ecologists, we will have to work on several fronts simultaneously to maintain the Earth system within a safe operating state (Rockstrom and others 2009), to build local resilience of ecosystems to global stressors (Scheffer and others 2015), and to facilitate the movement of species as environmental conditions change despite our efforts. This will likely be a path of inexorable contradictions, where we may have to accept new landscapes with new inhabitants in our once beloved lands.

\section{Challenges and Research Priorities}

The time has come to free the scientific discussion about tree expansion of value-laden attitudes. 'To Tree or not to Tree' is one of the most important societal questions that requires the help of ecologists today. It merits a professional forward looking and dispassionate attitude. To reach this goal, we need a combination of objective assessments of ecosystem services to avoid management actions grounded on assumptions instead of evidencebased science (Carpenter and others 2009), with open discussions on the risks of subjectivity resulting from how these ecosystem services are perceived and valued (Hobbs 2016). Despite generalized concern on the proliferation of trees and shrubs in grasslands and savannas, there is limited quantification and inconsistent results on their consequences for most of the ecosystem functions (Archer and Predick 2014). We echo the conclusions emerging from such earlier reflections. Now it is time to take the next step and structure research around a set of research questions (Table l; Figure 1), designed to provide society with the objective information needed to decide on the question posed in our title.

\section{OPEN ACCESS}

This article is distributed under the terms of the Creative Commons Attribution 4.0 International License (http://creativecommons.org/licenses/by/ $4.0 /$ ), which permits unrestricted use, distribution, and reproduction in any medium, provided you give appropriate credit to the original author(s) and the source, provide a link to the Creative Commons license, and indicate if changes were made.

\section{REFERENCES}

Archer SR, Predick KI. 2014. An ecosystem services perspective on brush management: research priorities for competing landuse objectives. J Ecol 102:1394-407.

Bernardi RE, Holmgren M, Arim M, Scheffer M. 2016. Why are forests so scarce in subtropical South America? The shaping roles of climate, fire and livestock. For Ecol Manag 363:21217.

Butterfield BJ, Camhi AL, Rubin RL, Schwalm CR. 2016. Tradeoffs and compatibilities among ecosystem services: biological, physical and economic drivers of multifunctionality. Adv Ecol Res 54:207-43.

Carpenter SR, Mooney HA, Agard J, Capistrano D, DeFries RS, Díaz S, Dietz T, Duraiappah AK, Oteng-Yeboah A, Pereira HM, Perrings C. 2009. Science for managing ecosystem services: beyond the Millennium Ecosystem Assessment. Proc Nat Acad Sci 106:1305-12.

Chamberlin TC. 1897. The method of multiple working hypotheses. J Geol 5:837-48.

Chen IC, Hill JK, Ohlemüller R, Roy DB, Thomas CD. 2011. Rapid range shifts of species associated with high levels of climate warming. Science 333:1024-6.

Darwin C. 1845. The Vogage of the Beagle. London: Marshall Cavendish Ltd. p 500p.

Fernández-Giménez ME. 2015. A shepherd has to invent: poetic analysis of social-ecological change in the cultural landscape of the central Spanish Pyrenees. Ecol Soc 20:29. doi:10.5751/ ES-08054-200429.

Hobbs RJ. 2016. Degraded or just different? Perceptions and value judgements in restoration decisions. Restor Ecol 24:153-8.

Hughes JD. 2011. Ancient deforestation revisited. J Hist Biol $44: 43-57$

Hutchings K. 2007. Ecocriticism in British romantic studies. Lit Compass 4:172-202.

Laestadius L, Saint-Laurent C, Minnemeyer S, Potapov P. 2011. A world of opportunity for forest and landscape restoration. The global partnership on forest landscape Restoration. World Resources Institute, South Dakota State University \& the International Union for the Conservation of Nature (Available at: http://pdf.wri.org/world_of_opportunity_brochure_201109.pdf).

MacDonald D, Crabtree JR, Wiesinger G, Dax T, Stamou N, Fleury P, Gutierrez Lazpita J, Gibon A. 2000. Agricultural abandonment in mountain areas of Europe: environmental consequences and policy response. J Environ Manag 59:4769. 
Millennium Ecosystem Assessment. 2005. Ecosystems and human well-being: synthesis. Washington (DC): Island Press. p $137 \mathrm{p}$.

Monbiot G. 2013. The lake district is a wildlife desert. Blame Wordsworth. The guardian (http://www.theguardian.com/ commentisfree/2013/sep/02/lake-district-wildlife-desert-blamewordsworth) (Accessed on 14 April 2016).

Ostrom E. 2008. Frameworks and theories of environmental change. Editorial. Glob Environ Chang 18:249-52.

Palomo I, Felipe-Lucia MR, Bennett EM, Martín-López B, Pascual U. 2016. Disentangling the pathways and effects of ecosystem service coproduction. Adv Ecol Res 54:245-83.

Parmesan C. 2006. Ecological and evolutionary responses to recent climate change. Ann Rev Ecol, Evol, Syst 37:637-69.

Plato (360 BC). Critias. (as translated by Benjamin Jowett http:// classics.mit.edu/Plato/critias.html; Accessed on 14 April 2016).

Rockstrom J, Steffen W, Noone K, Persson A, Chapin FS, Lambin EF, Lenton TM, Scheffer M, Folke C, Schellnhuber HJ, Nykvist B, de Wit CA, Hughes T, van der Leeuw S, Rodhe H, Sorlin S,
Snyder PK, Costanza R, Svedin U, Falkenmark M, Karlberg L, Corell RW, Fabry VJ, Hansen J, Walker B, Liverman D, Richardson K, Crutzen P, Foley JA. 2009. A safe operating space for humanity. Nature 461:472-5.

Rössler M. 2006. World heritage cultural landscapes: a UNESCO flagship programme 1992-2006. Landsc Res 31:333-53.

Scheffer M, Barrett S, Carpenter SR, Folke C, Green AJ, Holmgren M, Hughes TP, Kosten S, van de Leemput IA, Nepstad DC, van Nes EH, Peeters ETHM, Walker B. 2015. Creating a safe operating space for iconic ecosystems. Science 347:131719.

Veldman JW, Overbeck GE, Negreiros D, Mahy G, Le Stradic S, Fernandes GW, Durigan G, Buisson E, Putz FE, Bond WJ. 2015. Tyranny of trees in grassy biomes. Science 347:484-5.

Wordsworth W. 1888. The complete poetical works. London: Macmillan and Co., Bartleby.com, 1999. www.bartleby.com/ 145/. [Date of Printout].

Wulf A. 2015. The invention of nature: the adventures of Alexander van Humboldt, the lost hero of science. London: Editorial John Murray Publishers. p 473p. 